\title{
Sarcoidosis of the anterior visual pathway: successes and failures
}

\author{
MARK J GELWAN, * RODNEY I KELLEN, $\ddagger$ RONALD M BURDE, $\S$ \\ MARK J KUPERSMITH† \\ From the Departments of Neurology ${ }^{*}$ and Ophthalmology, ${ }^{*} \dagger$ New York Eye and Ear Infirmary, New York \\ University Medical Center, New York, NY and the Departments of Ophthalmology $¥$ and Neurology and \\ Neurological Surgery, $\S$ Albert Einstein College of Medicine, New York, NY, USA
}

SUMMARY Four patients with progressive visual deterioration were found to have sarcoidosis involving the anterior visual pathway. They all developed chiasmal dysfunction and bilateral optic neuropathy, which responded to megadose corticosteroid therapy. When an attempt was made to withdraw the corticosteroids, the patients experienced a recrudescence of visual dysfunction and were subsequently unable to tolerate the corticosteroid dose levels necessary to maximise their visual potential. Each patient was treated with high-voltage radiation therapy, totalling up to 4500 rads. The beneficial response obtained was temporary, and immunosuppressive therapy with azathioprine or chlorambucil was instituted, preventing further deterioration.

Sarcoidosis is an idiopathic granulomatous disease that is well known to affect the central nervous system (CNS). The frequency of CNS involvement in sarcoidosis is reported to be approximately $5 \% .^{1}$ Most of the manifestations of CNS sarcoidosis are a result of a granulomatous basilar meningitis with infiltration or compression of adjacent structures. This usually results in cranial nerve dysfunction, the seventh cranial nerve being most commonly involved. Optic nerve, optic chiasm, brain stem, pituitary, hypothalmus and cerebellum may also be affected. ${ }^{1}$ In addition, CNS sarcoidosis can also present as a mass lesion masquerading as a neoplasm with focal cortical, as well as diffuse cortical dysfunction (seizures). ${ }^{2}$ Sarcoidosis presenting solely in the anterior visual pathway without other ophthalmic or CNS signs is rare. ${ }^{34}$ In spite of this, we present four patients with intracranial optic nerve and chiasmal sarcoidosis all of whom complained of a visual loss as their first symptoms. Although corticosteroid therapy is considered to be the mainstay in the treatment of CNS sarcoidosis, ${ }^{5}$ our patients were unable to tolerate the doses of systemic corticosteroids necessary to prevent progressive visual loss. Alternative intervention was required to prevent visual loss. The role of radiation therapy and immun-

Address for reprint requests: Mark $J$ Kupersmith, MD, 530 First Avenue, Suite 3B, New York, NY 10016, USA.

Received 5 January 1988 and in revised form 6 June 1988. Accepted 13 June 1988 osuppressive (cytotoxic) therapy, their putative mechanisms and their effectiveness, are discussed.

\section{Case reports}

Case 1 (table 1) A 45 year old black woman experienced painful decrease of vision in the right eye for one month in August 1984. Initially, the vision deteriorated over one week but responded to oral prednisone $(80 \mathrm{mg}$ ) therapy given to her prior to our evaluation, which was when the visual loss recurred as the prednisone was reduced. She had no other neurological or general medical symptoms. Her past medical history included hypertension controlled by a low sodium diet.

Examination (by MJK) revealed a Snellen acuity of 20/40 in the right eye and 20/20 in the left. The colour vision was severely impaired in the right eye by Ishihara testing. Her pupils were $3 \mathrm{~mm}$ in size, round and reactive to light with a moderate relative afferent pupillary defect on the right side. The anterior segment and intraocular pressures were normal. Visual fields on a tangent screen at $1 \mathrm{~m}$ demonstrated a generalised constriction in the right eye to the $2 \mathrm{~mm}\left(10^{\circ}\right)$ and $5 \mathrm{~mm}\left(15^{\circ}\right)$ white test objects; the visual field of the left eye was normal. Ophthalmoscopic evaluation revealed diffuse yellow pallor of the right optic disc with a diffuse, mild thinning of the nerve fiber layer and a normal left eye fundus. The prednisone was reinstituted at $80 \mathrm{mg}$ a day. The remainder of her neurological evaluation and blood pressure were normal.

Blood laboratory tests, including haemogram, erythrocyte sedimentation rate, antinuclear antibody, VDRL, FTAABS, latex fixation and angiotensin converting enzyme, were negative. A chest radiograph showed fullness bilaterally in 
Table 1 Case 1

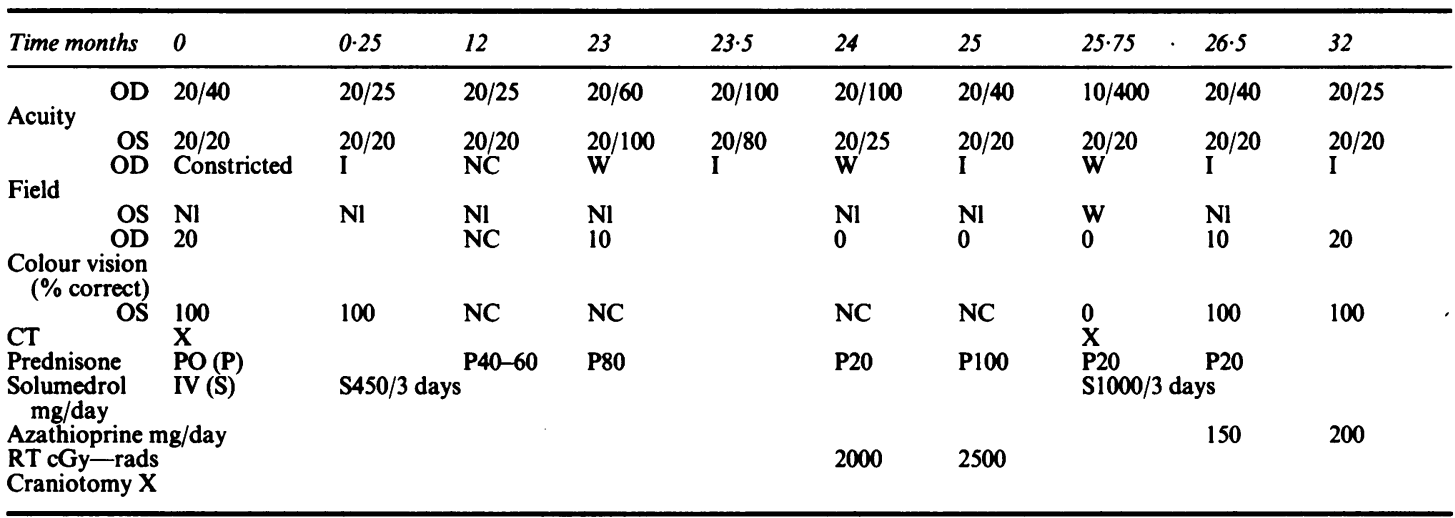

$\mathrm{Nl}=$ Normal $\mathbf{I}=$ Improved $\mathbf{W}=$ Worse $; \mathrm{NC}=$ No Change.

the hilar region. A contrast CT scan of the head and orbits demonstrated pansinusitis and an enhancing mass in the area of the planum sphenoidale and olfactory groove that extended into the right orbit. (fig 1).

At craniotomy a mass was seen involving the tuberculum sellae and suprasellar area as well as the right carotid artery. The surgeon thought the lesion was inflammatory in nature, and it could not be separated from the carotid artery. A partial resection was performed to decompress the right optic nerve and chiasm. Histopathology showed chronic noncaseating granulomatous disease consistent with the diagnosis of sarcoidosis. Perioperative intravenous solumedrol
$120 \mathrm{mg}$ four times daily was reduced and she was discharged on $80 \mathrm{mg} /$ day of prednisone orally. Her 20/25 acuity and visual field remained stable for 2 years on prednisone but any attempt to decrease the dose below $\mathbf{4 0} \mathrm{mg}$ daily resulted in visual deterioration. Hydrochlorothiazide was required to control a rise in the blood pressure. The fasting blood sugar fluctuated between $200 \mathrm{mg} / 100 \mathrm{ml}$ and $300 \mathrm{mg} / 100 \mathrm{ml}$.

The patient developed a left hemiparesis and left facial weakness one year after surgery in August 1985. A right cerebral infarction seen on CT was presumed to be associated with the systemic hypertension or was secondary to the granulomatous process involving the carotid artery. The

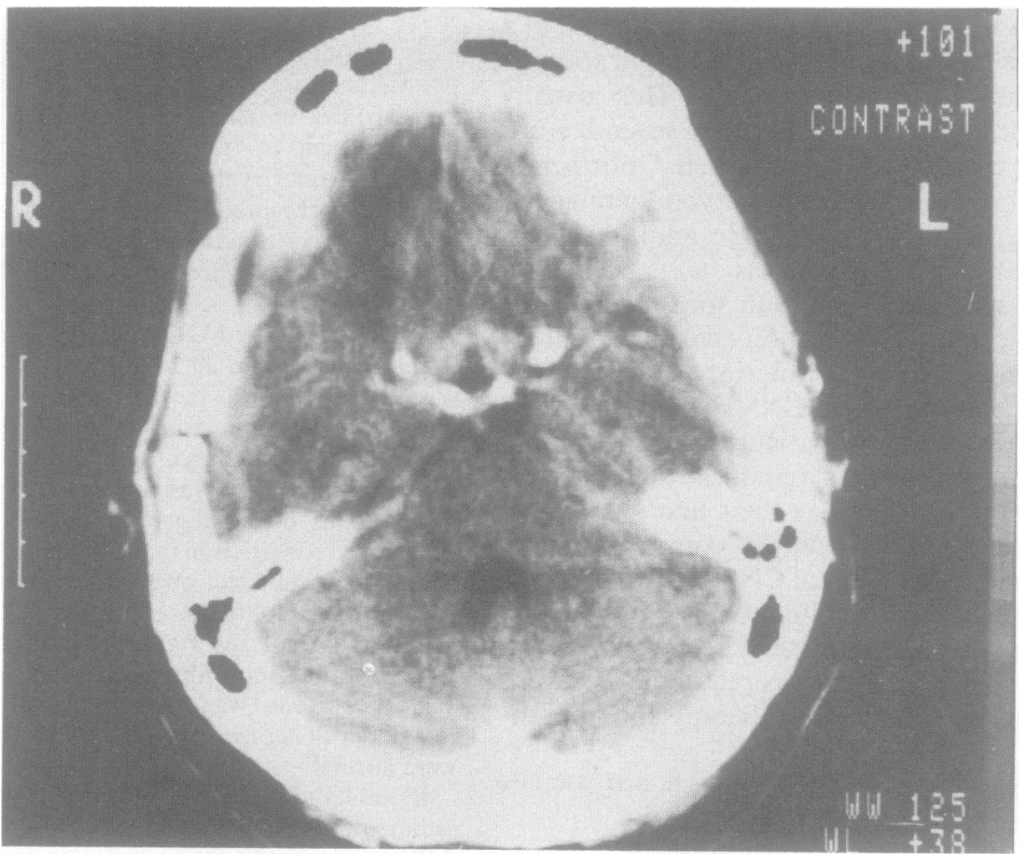

Fig 1 High resolution CT shows an enhancing mass in the suprasellar cistern. 
patient refused angiography but recovered her motor function over 30 days without any additional treatment. Eleven months later, despite $80 \mathrm{mg}$ of prednisone daily, the visual acuity decreased to $20 / 60$ in the right eye. Her visual field in the right eye was markedly constricted and only the central nasal $5^{\circ}$ and $8^{\circ}$ remained to $5 \mathrm{~mm}$ and $10 \mathrm{~mm}$ white test objects, respectively. Her colour vision was normal in the left eye, but was severely compromised in the right eye.

Owing to the failure of other therapeutic measures, it was elected to try focused, high voltage radiation therapy. She was given $2000 \mathrm{cGy}$ of radiotherapy in $200 \mathrm{cGy}$ fractions daily to the right sphenoid wing and suprasellar cistern areas. Immediately after the radiotherapy, the acuity was 20/40 and the field expanded temporally and nasally to between $10^{\circ}$ and $15^{\circ}$ to a $5 \mathrm{~mm}$ white object.

One month later, while on prednisone $20 \mathrm{mg}$ daily, her acuity deteriorated to $20 / 100$ in the right eye, colour vision was absent, and the visual field narrowed to a $5^{\circ}$ field nasal to fixation to a $5 \mathrm{~mm}$ white. The left eye was unchanged. The prednisone was increased to $100 \mathrm{mg}$ per day, and an additional 2,500 cGy of radiotherapy to the anterior cranial fossa was given in $200 \mathrm{cGy}$ daily fractions. One month later, while on $80 \mathrm{mg}$ prednisone, the visual acuity in the right eye improved to 20/40, and the visual field expanded to $10^{\circ}$ nasally and $15^{\circ}$ temporally to a $5 \mathrm{~mm}$ white object. The prednisone was gradually reduced and she was maintained on $20 \mathrm{mg}$ daily.

Three weeks later on December 4 1986, she returned with pain in her left eye, headache and diminished vision in both eyes for three days. Her visual acuity was 10/400 in the right eye and 20/200 in the left, with absent colour vision. Funduscopy showed diffuse yellow pallor of the disc and nerve fibre loss in the right eye. The left fundus was normal. The visual fields were untestable in right and only $8^{\circ}$ of field remained nasal to fixation in the left eye to a $5 \mathrm{~mm}$ white. She was hospitalised and given $250 \mathrm{mg}$ of intravenous methylprednisolone four times daily for 3 days with improvement of her vision to 20/40 in the right eye and 20/20 in the left with normalization of the field in the left eye and expansion of the field in the right eye to $10^{\circ}$ to a $5 \mathrm{~mm}$ white and $5^{\circ}$ to a $2 \mathrm{~mm}$ white. Colour vision became normal in the left eye. She was begun on oral azathioprine, $100 \mathrm{mg}$ per day, and the prednisone was lowered to $60 \mathrm{mg}$ daily. The azathioprine was increased over one month to $200 \mathrm{mg}$ without change in her haemogram except for a fall in her lymphocytes to $13 \%$ from
$30 \%$. Her most recent examination eight months after beginning azathioprine, on a gradually lowered prednisone dose $(10 \mathrm{mg} /$ day), revealed visual acuity of $20 / 25$ in the right eye and 20/20 in the left. She had normal colour vision in both eyes. A moderate afferent pupillary defect in the right eye remained. Her visual fields expanded to $10^{\circ}$ superiorly and $5^{\circ}$ inferiorly with the right eye and was normal with the left eye. She was normatensive, without antihypertensive drugs, and her blood glucose was normal.

Case 2 (table 2) A 32 year old black man was evaluated in June 1985 for progressive visual loss in the right eye over several months despite $\mathbf{4 0} \mathrm{mg}$ prednisone. The history began in January 1984 with a prednisone (dose unknown) responsive "papillitis" that caused visual loss in the left eye resulting in blindness in March 1984. He had no other neurological complaints.

His examination (by MJK) revealed corrected Snellen acuity of 20/40 with his right eye and no light perception with his left eye. His pupils were $5 \mathrm{~mm}$ and round; the right pupil reacted to light; the left pupil was amaurotic but reacted consensually. The anterior segment and intraocular pressures were normal. He had a mild colour defect to the Ishihara colour plates with his right eye. Visual fields on a tangent screen at one meter revealed a complete temporal defect to the $5 \mathrm{~mm}$ white test object and constriction temporally to $10^{\circ}$ from fixation to a $10 \mathrm{~mm}$ white test object. The right optic disc was mildly pale temporally, and there was a mild diffuse decrease in the nerve fibre layer. The left disc was pale yellow with absent nerve fibre layer and arteriolar narrowing, worse inferiorly. There was venous sheathing peripherally in both eyes. The remainder of the neurological examination was normal.

Contrast CT of the head showed an enlarged optic chiasm (fig 2). Erythrocyte sedimentation rate, ANA, FTA-ABS, VDRL, and CBC, were normal but the angiotensin converting enzyme was raised $(127 \mathrm{IU} / \mathrm{ml}, \mathrm{nl} 12-36)$. The chest radiograph showed hilar adenopathy. The lumbar puncture opening pressure was $180 \mathrm{~mm} \mathrm{H}_{2} \mathrm{O}$. The spinal fluid had 20 WBCs (100\% mononuclear cells), protein $31 \mathrm{mg} / \mathrm{dl}$, and glucose $50 \mathrm{mg} / \mathrm{dl}$, no oligoclonal bands and a negative VDRL. Pulmonary evaluation included a bronchoscopic biopsy that revealed noncaseating granulomas consistent with sarcoidosis.

He was treated with $250 \mathrm{mg}$ of intravenous methylpredn-

Table 2 Case 2

\begin{tabular}{|c|c|c|c|c|c|c|c|c|c|c|}
\hline Time months & 0 & 0.1 & 12 & 13 & 15 & $15 \cdot 2$ & $15 \cdot 5$ & 17 & 19 & 22 \\
\hline OD & $20 / 40$ & $20 / 30$ & $20 / 100$ & $20 / 50$ & $20 / 100$ & $20 / 100$ & $20 / 80$ & $20 / 200$ & & $20 / 60$ \\
\hline $\begin{array}{ll} & \text { OS } \\
\text { Field } & \text { OD }\end{array}$ & $\begin{array}{l}\text { NLP } \\
\text { Temporal loss }\end{array}$ & $\begin{array}{l}\text { NLP } \\
\text { I }\end{array}$ & $\underset{\mathbf{W}}{\mathbf{N L P}}$ & $\begin{array}{l}\text { NLP } \\
\text { NC }\end{array}$ & $\underset{\mathbf{W}}{\mathbf{N L P}}$ & $\begin{array}{l}\text { NLP } \\
\text { NC }\end{array}$ & $\underset{\text { I }}{\text { NLP }}$ & $\underset{\mathbf{W}}{\mathbf{N L P}}$ & & $\underset{\text { I }}{\text { NLP }}$ \\
\hline $\begin{array}{l}\text { Colour vision } \\
\text { (\% correct) }\end{array}$ & 80 & 100 & & & 0 & & & 0 & & 0 \\
\hline $\begin{array}{l}\text { Prednisone } \\
\text { PO (P) } \\
\text { Solumedrol } \\
\text { mg/day }\end{array}$ & $\begin{array}{l}\text { P40 } \\
\text { IV (S) }\end{array}$ & $\begin{array}{l}\text { P80 } \\
\text { S1000 } \\
3 \text { days }\end{array}$ & P60 & P30 & P30 & $\begin{array}{l}\text { S1000 } \\
4 \text { days }\end{array}$ & P40 & P40 & P80 P80 & P10 QOD \\
\hline $\begin{array}{l}\text { Azathioprine } \\
\text { mg/day } \\
\text { RT cGy-rads }\end{array}$ & & & 2000 & & & & 2500 & & 100200 & 200 \\
\hline
\end{tabular}

$\mathrm{Nl}=$ Normal; $\mathrm{I}=$ Improved $\mathbf{W}=$ Worse $; \mathrm{NC}=$ No Change; NLP = No Light Perception. 
Table 3 Case 3

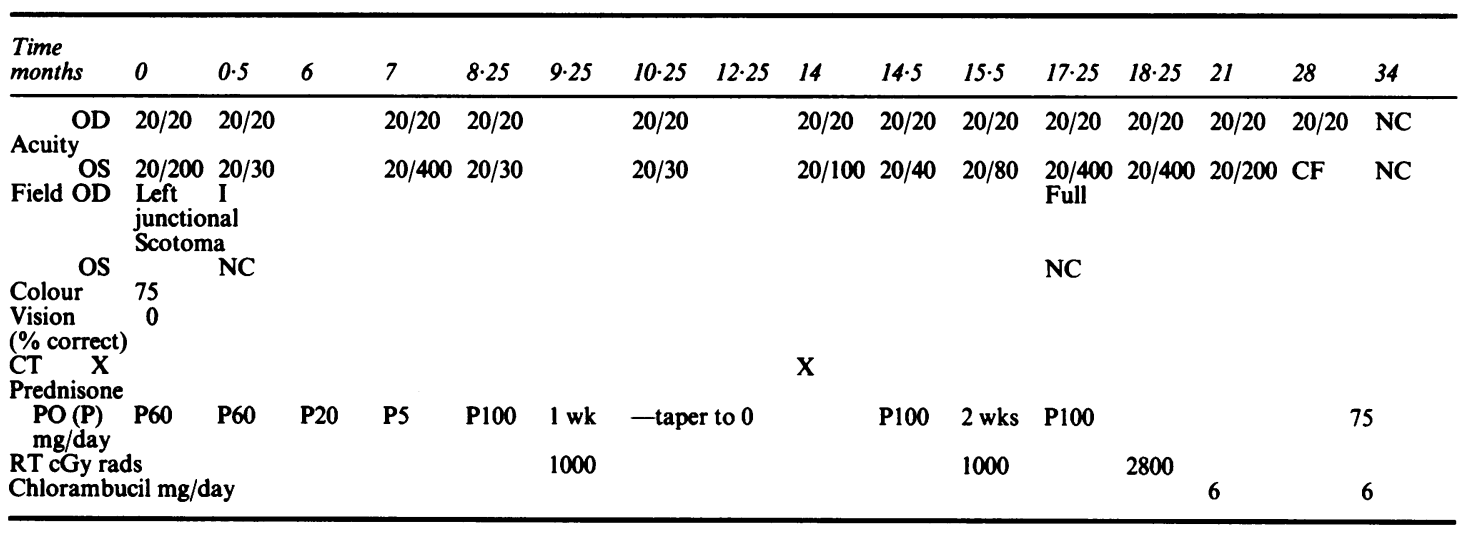

$\mathrm{I}=$ Improved; $\mathrm{NC}=$ No Change; $\mathrm{CF}=$ Count fingers.

isolone four times daily. In 3 days, the acuity in his right eye improved to 20/30 with normal colour vision and expansion of his visual field to $15^{\circ}$ to a $2 \mathrm{~mm}$ white and $25^{\circ}$ to a $5 \mathrm{~mm}$ white test object. The steroids were reduced over one week and he was discharged on prednisone $80 \mathrm{mg} /$ day orally and returned to his referring physicians.

Over the next year the visual loss recurred in his right eye whenever the steroid dosage was decreased to $60 \mathrm{mg}$ daily. He became markedly cushingoid, diabetic requiring insulin, and developed intraocular pressure elevation to $25 \mathrm{mmHg}$ bilaterally. In May 1986, when the acuity diminished to
$20 / 100$ on $60 \mathrm{mg}$ prednisone daily, the dose was increased to $200 \mathrm{mg}$ daily and he was given $2,000 \mathrm{cGy}$ of radiotherapy in 200 cGy daily fractions to the anterior cranial fossa. His acuity improved to $20 / 50$ without change in his field for one month after radiotherapy, while on $30 \mathrm{mg}$ of oral prednisone daily.

Over the next two months, he noticed a progressive decrease in vision to an acuity of $20 / 100$. Only the $5^{\circ}$ superonasal to fixation remained on perimetry with a $5 \mathrm{~mm}$ white test object. He could only "count fingers" in the remainder of the field. He was hospitalised on 5 November

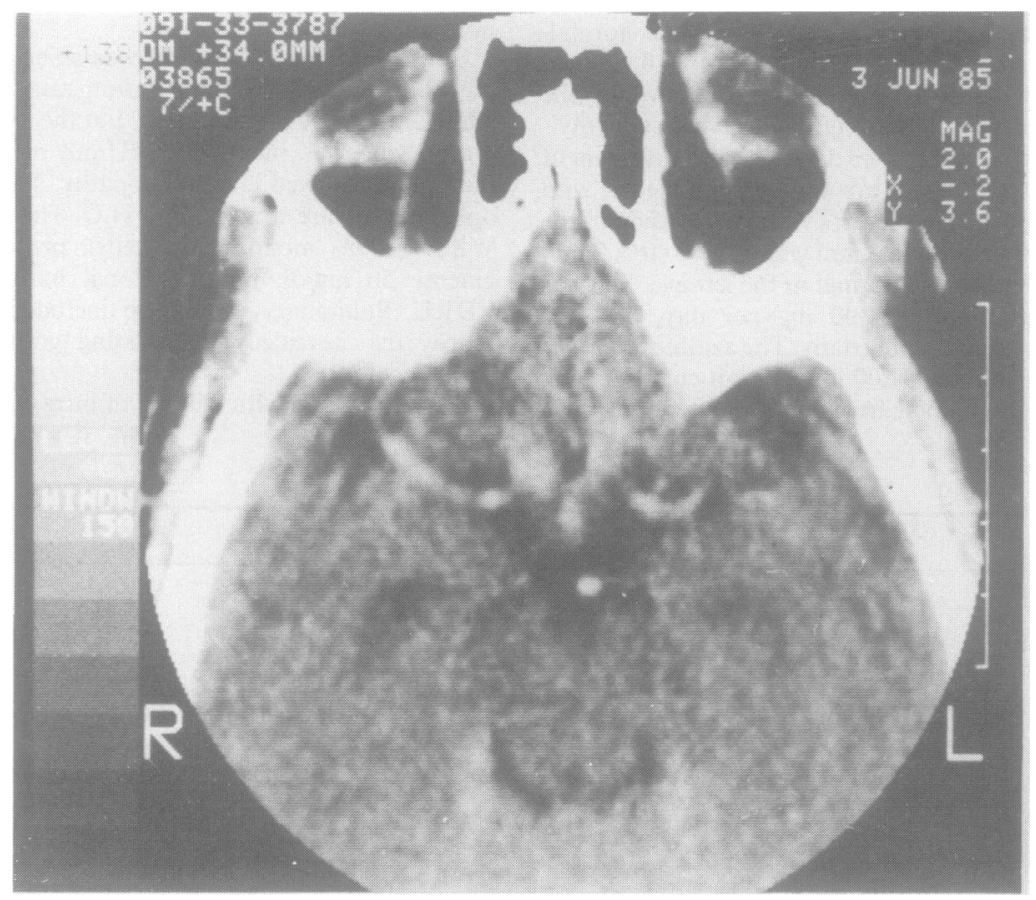

Fig 2 High resolution CT demonstrates enhancement and thickening of the chiasm and intracranial optic nerves. 
1986 and treated with $250 \mathrm{mg}$ of intravenous methylprednisolone four times daily for 4 days with little improvement in acuity or visual field. An additional $2500 \mathrm{cGy}$ in $200 \mathrm{cGy}$ fractions through lateral parallel opposed fields were delivered to the anterior cranial fossa. The vision stabilised at $20 / 80$, and the field expanded to $5^{\circ}$ above fixation with a $5 \mathrm{~mm}$ white test object. The steroids were reduced during radiation treatment, and by mid December 1986 he was on $40 \mathrm{mg}$ of oral prednisone daily.

Six weeks after radiotherapy the Snellen visual acuity fell to $20 / 200$, and the visual field constricted so that only a $5^{\circ}$ island nasal to fixation could be demonstrated with a $5 \mathrm{~mm}$ white test object. He was started on $100 \mathrm{mg}$ of azathioprine daily, and the dose of prednisone was increased to $80 \mathrm{mg}$ daily. The azathioprine was increased over two months to $200 \mathrm{mg}$. In spite of this, the total white blood count remained at $10,000 / \mathrm{mm}^{3}$, but the percentage of lymphocytes fell to $4 \%$. Five months after starting the azathioprine the prednisone had been reduced to $10 \mathrm{mg}$ every other day. His visual acuity was $20 / 60$, and the nasal field was expanded four-fold, as measured with a $5 \mathrm{~mm}$ white test object. He is no longer cushingoid and requires no insulin.

Case 3: (table 3) A 20 year old black man presented in June 1984 complaining of progressive visual loss in his left eye over the prior six months. He had a continuous dull frontal headache and bilateral periorbital pain. He had symptoms of panhypopituitarism, including impotence, hair loss (scalp, public and axillary), somnolence and dry pruritic skin. He denied polyuria or polydipsia. Possible pertinent past medical history included infectious hepatitis at age 16 years.

Examination (by RMB) revealed a healthy looking black man. Corrected Snellen acuity was $20 / 20$ in the right eye and $20 / 200$ in the left. Brightness discrimination and colour saturation were decreased by $50 \%$ in the left eye compared with the right. The right eye colour vision was mildly abnormal, but with the exception of the control plate he could not identify any of the pseudoisochromatic plates with his left eye. Both pupils were round, equal and reacted to light. A relative afferent pupillary defect was present in the left eye. The anterior segment was normal. Applanation pressures were $9 \mathrm{~mm} \mathrm{Hg}$ in the right eye and $11 \mathrm{~mm} \mathrm{Hg}$ in the left.

The optic discs in both eyes had pale temporal rims, a cup/ disc ratio of 0.7 in the horizontal and vertical meridians and diffuse nerve fibre layer dropout. The maculas and peripheral retinas were normal bilaterally. Kinetic visual fields performed on the Goldmann perimeter showed a left junctional scotoma, central scotoma to $\mathrm{I}_{2} \mathrm{e}$ and $\mathrm{I}_{4} \mathrm{e}$ with the left eye and superior temporal depression to a $\mathrm{I}_{2} \mathrm{e}$ with the right eye. The neurological examination was otherwise normal.

Contrast enhanced CT demonstrated an enhancing midline mass in the suprasellar cistern (fig 3 ) and a convexity of the diaphragma sellae, suggesting a "dumbbell"-shaped

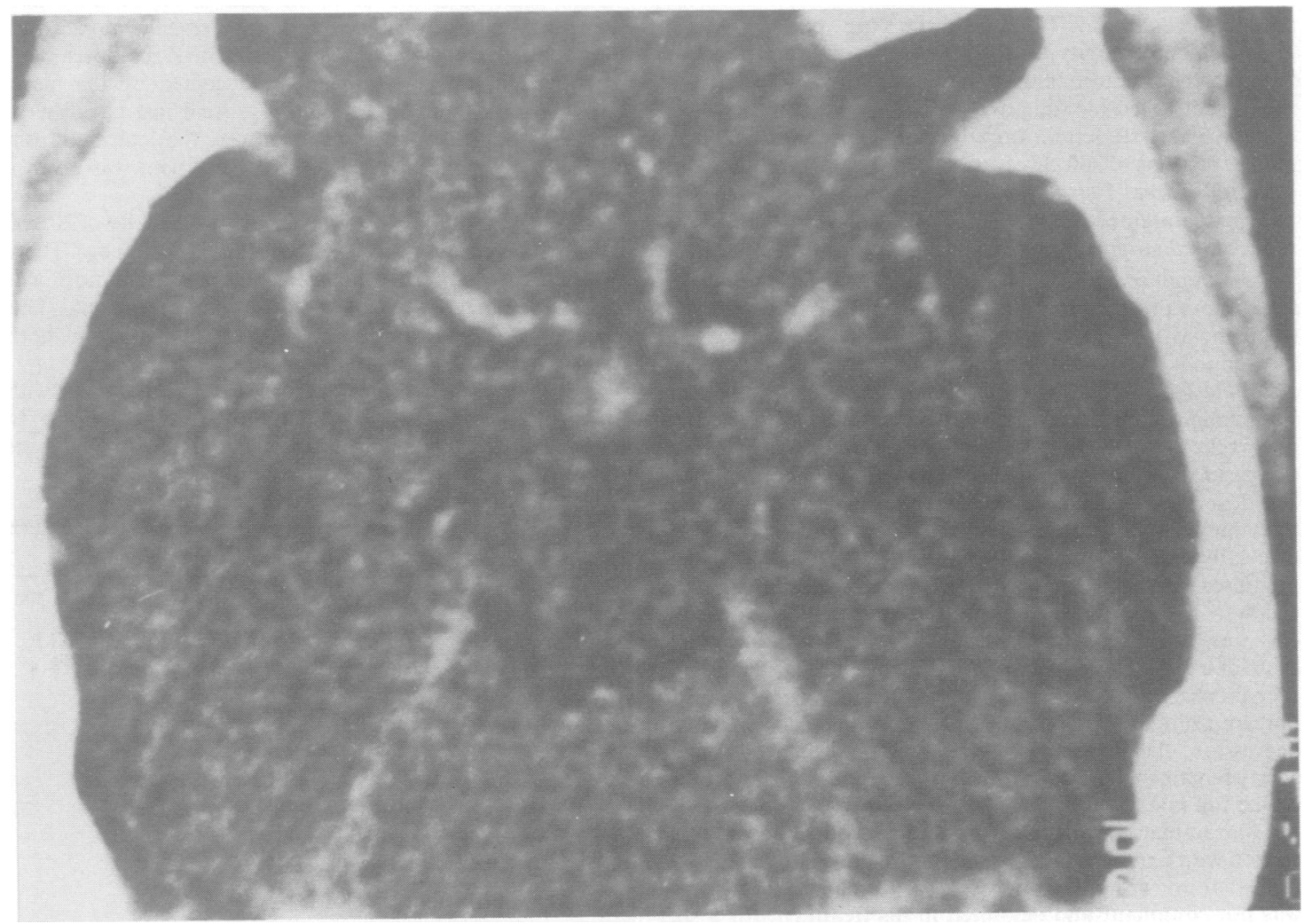

Fig 3 High resolution CT showing an enhancing mass in the suprasellar cistern. 
lesion. Hilar and mediastinal lymphadenopathy were present on chest radiograph. Blood laboratory evaluation demonstrated selective hypopituitarism with a low testosterone and cortisol as well as a subnormal thyroid-stimulating hormone response to exogenous thyrotropin release factor, despite a normal free thyroxine index. Serum angiotensin converting enzyme was $181 \mathrm{mmol} / \mathrm{min} \mathrm{ml}$ (normal 20-68), and lactic acid dehydrogenase was 295 (normal, 110-120).

A gallium scan showed increased uptake in the mediastinum and bilateral hilar regions as well as in the lachrimal area, nasopharynx, ethmoid sinuses and suprasellar regions. A lymph node biopsy performed during mediastinoscopy demonstrated noncaseating granulomas compatible with a diagnosis of sarcoidosis.

He was treated with $60 \mathrm{mg}$ of oral prednisone per day as well as thyroid and testosterone supplementation. Within two weeks his vision improved to $20 / 30$ in the left eye, but he still had the relative afferent pupillary defect and desaturation of colour in that eye. Kinetic perimetry showed resolution of the junctional scotoma. The prednisone was tapered to $20 \mathrm{mg}$ daily, and he was maintained on this dose for five months. He became markedly cushingoid but he was not hypertensive, nor did he develop hyperglycaemia. The steroids were further tapered to $5 \mathrm{mg}$ per day over the next month.

Examination of his left eye at this time revealed a deterioration of both his visual acuity $(20 / 400)$ and his visual field with the return of the junctional scotoma. The oral prednisone was increased to $100 \mathrm{mg}$ per day with improvement in acuity to 20/30 within one week. In spite of tapering the prednisone over the ensuing four week period, the patient noted bloating, weight gain and a recrudescence of his visual dysfunction. Low dose radiotherapy, 1,000 cGy in five fractions of $200 \mathrm{cGy}$ was delivered to the pituitary and suprasellar area. Two weeks following radiation therapy, the patient maintained 20/30 vision. The steroids were further reduced and stopped after two months.

The patient remained stable until August 1985 (14 months after initial presentation and 3 months after radiotherapy), when the vision in his left eye deteriorated to $20 / 100$. CT showed that the suprasellar enhancing mass, presumed to be a sarcoid granuloma, was still present but not increased in size. Oral prednisone, $100 \mathrm{mg}$ per day, was started and within two weeks the vision in the left eye improved to 20/40. During the period of steroid-taper his vision deteriorated to 20/80. The dose of prednisone was increased to $100 \mathrm{mg}$ per day, and the same area was irradiated with an additional $1,000 \mathrm{cGy}$ in five daily fractions of $200 \mathrm{cGy}$. In spite of the continued prednisone therapy there was a further deterioration of vision to $20 / 400$ over the next six weeks. An additional 2,880 cGy were given to the same area in 16 fractions of $180 \mathrm{cGy}$, each for a total dose of $4,880 \mathrm{cGy}$. Concomitantly, because of ever increasing intolerance to the systemic corticosteroids, that is cushingoid appearance, weight gain and psychological depression, the patient was weaned from their use. Visual acuity remained at $20 / 400$ in the left eye and 20/20 in the right with a full kinetic visual field.

Chlorambucil, $6 \mathrm{mg}$ daily in three divided doses, was started with a modest improvement in visual acuity to 20/200 in the left eye within three weeks. Unfortunately, the patient was not compliant and defaulted in his treatment for a six month period. He returned in September, 1986, and the vision in his left eye was decreased to "finger counting at 1 foot $(30 \mathrm{~cm}$ )" but was $20 / 25$ with full kinetic and threshold static fields in his right eye. The patient refused biopsy of the lesion in the supra- and parasellar area still present on repeat CT. Chlorambucil, $6 \mathrm{mg}$ per day, and low dose steroids, $7 \frac{1}{2}$ mg per day were started. His white blood count was maintained below $3000 / \mathrm{mm}^{3}$. When last examined, in May, 1987 (three years after presentation), his visual acuity and field had been stable for six months on this treatment regimen.

Case 4 (table 4) The total clinical history of this patient is somewhat obfuscated because he consulted many physicians in different parts of the country without informing them of his previous examinations, results of laboratory tests, neuroimaging examinations, and current or past use of medications. No single physician coordinated his overall management. When we first saw the patient his medications included oral prednisone, $\mathbf{4 0} \mathrm{mg}$ daily, oral hypoglycaemic agents, and thyroid supplements.

This, then 34-year-old black man was first evaluated in St. Louis in April, 1981, for a complaint of decreasing vision in both eyes over a 7 year period. In 1974 the patient had a weakly positive serum VDRL and FTA-ABS but all the cerebrospinal fluid studies were normal. He was treated with $7 \cdot 2$ million units of long acting penicillin in three divided intra-muscular weekly doses.

Five years later in 1979, he had a craniotomy and intracranial biopsy. The histopathology revealed noncaseating granulomatous changes suggestive of sarcoidosis. This interpretation was not universally accepted by the many pathologists who studied the biopsy. Acid fast bacilli were never seen on the slides, and neither were they cultured from the biopsy specimen. Nevertheless, the patient was given a trial of INH and rifampicin for six months.

The examination by RMB revealed visual acuity of 20/200 in the right eye and "no light perception" in the left eye. There was a large left exotropia. Slit lamp examination was remarkable only for bilateral posterior subcapsular lens opacities. Applanation pressures were $22 \mathrm{~mm} \mathrm{Hg}$ in both eyes.

The optic disc in the left eye was chalk-white with attenuated blood vessels. The right disc was diffusely pale. In neither eye was there evidence of chorioretinitis or changes

Table 4 Case 4

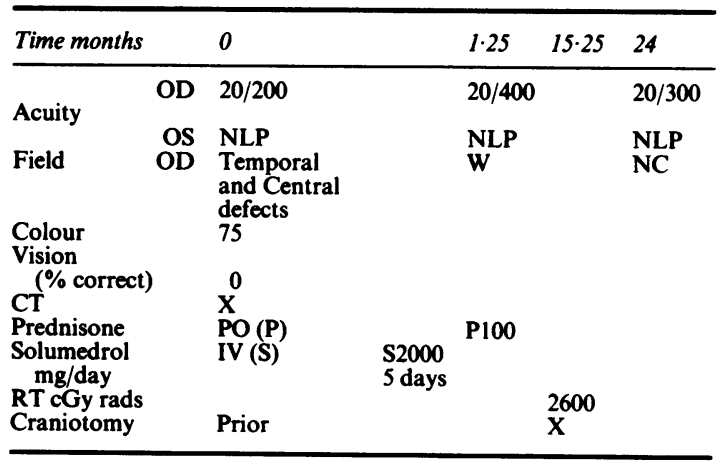

$\mathrm{W}=$ Worse NC $=$ No Change NLP $=$ No Light Perception. 


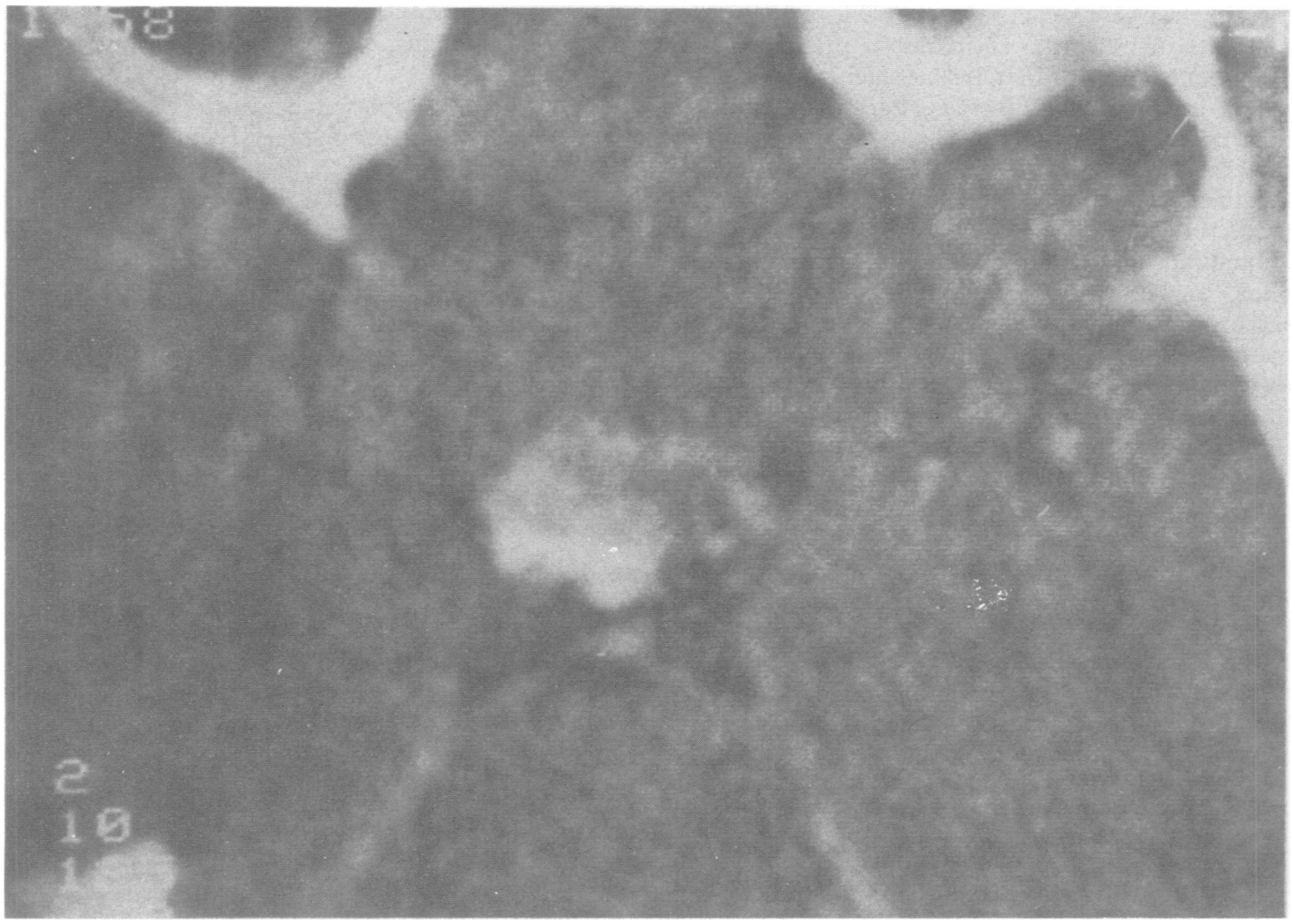

Fig 4 High resolution CT scan showing a large enhancing mass in the suprasellar cistern. The mass is more prominent on the left.

indicative of previous episodes of inflammation. The right kinetic visual field performed on the Goldmann perimeter demonstrated a temporal hemianopia and a central scotoma to $\mathrm{I}_{3} \mathrm{e}, \mathrm{III}_{4} \mathrm{e}$, and $\mathrm{V}_{4} \mathrm{e}$ isopters. Contrast $\mathrm{CT}$ showed an enhancing suprasellar mass, more prominent on the left, consistent with a sarcoid granuloma (fig 4).

The patient was treated with $1,000 \mathrm{mg}$ of intravenous methylprednisolone every 12 hours for five days. He was discharged on oral prednisone, $100 \mathrm{mg}$ daily for one month. Despite this therapy, visual acuity in the right eye deteriorated further to $20 / 400$ with loss of the superior part of the remaining nasal field.

Another exploratory craniotomy was performed in July, 1982, at the University of Nebraska. Biopsy of tissue in the suprasellar area confirmed the diagnosis of sarcoidosis. Because of continued subjective deterioration, a course of radiation therapy was delivered to the suprasellar area with a total dose of $2,600 \mathrm{cGy}$ in $200 \mathrm{cGy}$ fractions.

For eight months, the visual acuity in his right eye remained stable at $20 / 300$. The kinetic visual field was also unchanged during this time. Unfortunately, this patient was "lost to follow up", despite many attempts to communicate with him.

\section{Discussion}

Central nervous system sarcoidosis with involvement of the anterior visual pathways is well documented but unusual. $^{2-5}$ The difficulty is making the diagnosis of anterior afferent visual system sarcoidosis is also well known. ${ }^{256}$

All of our patients presented with poor vision and initially responded to corticosteroids. The patients either were unable to tolerate the steroids, or their vision deteriorated when attempts were made to wean them because of systemic side effects. Because of steroid failure or side effects, or both, radiation therapy was used as an additional treatment modality in our four cases. ${ }^{78}$ Metabolically active cells, found in inflammatory granulomas or neoplastic tissues, are more susceptible to damage from radiotherapy than stable cell populations, such as those in the normal central nervous system. In view of earlier reported success with the use of radiotherapy in cases of CNS sarcoidosis, ${ }^{78}$ it is not clear why our patients experien- 
ced only transient benefits. It is possible our cases had a more virulent form of sarcoidosis presenting as a localised mass rather than the meningitic form, reported to respond to radiotherapy. Perhaps visual function in Case 4 was irreversibly lost prior to receiving radiotherapy, or possibly some inflammatory cells remained unaffected by the radiation and continued to proliferate.

Immunosuppression with azathioprine or chlorambucil, our next form of therapy, appeared to be successful in the short term. Reports of chlorambucil, 9 methotrexate, ${ }^{10}$ azathioprine, ${ }^{11}$ and chloroquine, ${ }^{12}$ used alone or in addition to corticosteroids in the treatment of sarcoidosis located outside the CNS, show variable results. The mechanism of action of these drugs must relate to an effect on the immunopathology of sarcoidosis, which is yet to be fully understood. There are three possible sites where immunotherapy may alter the granulomatous process. A type IV delayed hypersensitivity reaction characterised by fibrinogen deposition' has been established. A type II cytotoxic (cell stimulating) reaction in response to an unknown antigen is indicated by immunofluorescent demonstration of immunoglobulin and complement (specifically $\mathrm{C}_{3}$ and $\mathrm{C}_{4}$ ) in the sarcoid granuloma. ${ }^{13}$ An angiitic form of neurosarcoidosis also has been reported..$^{14} 15$ True arthus-type antigen antibody immune complex deposition in the blood vessels may be the cause, but there is no pathological confirmation of this hypothesis. ${ }^{13}$

Corticosteroids may prevent granuloma formation by suppressing the synthesis of lymphokines and by blocking the action of lymphokines on monocytes, so their migration is inhibited. ${ }^{16}$ Cytotoxic (immunosuppressive) agents reduce the number of available mononuclear cells by suppressing bone marrow activity. The reduction of mononuclear cells responsible for the cytotoxic, type II, immune response may explain the effectiveness of these agents in our cases. It is also known that these cytotoxic agents may potentiate the anti-inflammatory effect of steroids by altering several steps in the pathway of chronic inflammation.?

Sarcoidosis of the intracranial anterior visual pathway occurs infrequently and is often difficult to diagnose, but once the diagnosis is established, intensive therapy should be considered. Despite systemic corticosteroid and radiation therapy, blindness can occur, and long term use of corticosteroids is poorly tolerated by patients. Early institution of immuno- suppressive therapy may prevent permanent visual loss in these patients.

This work was supported by Research to Prevent Blindness, Inc. and the Surgery Fund of the Kirby Laboratory Fund.

\section{References}

1 Delaney P. Neurologic manifestations in sarcoidosis. Ann Intern Med 1977;87:336-45.

2 McLaurin EB, Harrington DO. Intracranial sarcoidosis with optic tract and temporal lobe involvement. Am J Ophthalmol 1978;86:656-60.

3 Graham EM, Ellis CJK, Sanders MD, McDonald WI. Optic neuropathy in sarcoidosis. J Neurol Neurosurg Psychiatry 1986;49:756-63.

4 Krohel GB, Charles H, Smith RS. Granulomatous optic atrophy. Arch Ophthalmol 1981;99:1053-5.

5 Tang RA, Grotta JC, Lee KF, Lee YF. Chiasmal syndrome in sarcoidosis. Arch Ophthalmol 1983;101: 1069-73.

6 Frisen L, Lingren S, MacGregor BJL, Stattin S. Sarcoidlike-disorder of intracranial optic nerve. J Neurol Neurosurg Psychiatry 1977;40:702-7.

7 Bejar JM, Kerby GR, Ziegler DK, Festoff BW. Treatment of central nervous system sarcoidosis with radiotherapy. Ann Neurol 1985;18:258-60.

8 Grizzanti JN, Knapp AB, Schechter AJ, Williams MH. Treatment of sarcoid meningitis with radiotherapy. $\mathrm{Am}$ J Med 1982;23:605-8.

9 Kalaria YP. Chlorambucil in sarcoidosis. Chest 1980; 78:36-43.

10 Lacher MJ. Spontaneous remission or response to methotrexate in sarcoidosis. Ann Intern Med 1968; 63:1247-8.

11 Krebs VP, Abel H, Schonberger W. Behandlung Boekschen Sarkoidose mit immunosuppressiven Substanzen. Munchener Medizurische Wochenschritt 1969;111: 2307-11.

12 Morse S, Cohn Z, Hirsch J, Schaedler R. The treatment of sarcoidosis with chloroquine. Am J Med 1961;30: 779-84.

13 Kalaria YP, Zafranas A, Sharma H. Immunohistochemistry of human cutaneous sarcoidosis. A study of nine cases. Hum Pathol 1978;9:517-22.

14 Caplan C, Corbett J, Goodwin C, et al. Neuro-ophthalmologic signs in the angiitic form of neurosarcoidosis. Neurology 1983;33:1130-5.

15 Cravioto H, Feig JI. Non-infectious granulomatous angiitis with a predilection for the nervous system. Neurology 1959;9:599-609.

16 Fanfurg BL. Drug therapy reviews, treatment of sarcoidosis. Am J Hosp Pharm 1979;36:351-54. 